\title{
Bibliografia comentada sobre qualidade da/na educação
}

Silvana Malheiro do Nascimento Gama Alba Valéria Baensi

ABDIAN, Graziela Zambão; NASCIMENTO, Paulo Henrique Costa. Gestão e qualidade da educação escolar básica: sentidos em construção. Revista Espaço Pedagógico, Passo Fundo, RS, v. 24, n. 2, p. 295-313, maio/ago. 2017. Disponível em: < http:// seer.upf.br/index.php/rep/article/view/7416>. Acesso em: 15 jun. 2020.

Artigo de revisão sobre formação, função e formas de provimento de cargos de diretores e suas inferências na qualidade do ensino da escola pública, em perspectivas histórica e contemporânea. Discutem-se os sentidos produzidos sobre gestão e qualidade pelo campo da gestão educacional e constata-se que, mesmo com o predomínio do discurso acadêmico acerca da criticidade na análise do contexto político, social e escolar, preserva-se a produção de conhecimento similar ao referencial que é criticado. As três concepções teórico-metodológicas descritas - a sociologia das organizações escolares ou a escola como organização educativa; a instituição escolar; e os estudos nos/dos/com os cotidianos escolares -, apresentam suas limitações quando se encontram com a escola e seus diferentes atores e atuações. As relações entre os sentidos em construção no campo da gestão e os sentidos em construção pelas/nas escolas públicas municipais fundamentam a análise dos sentidos construídos por diferentes integrantes de escolas, utilizando os critérios do salto no Índice de Desenvolvimento da Educação Básica (Ideb) e as diferentes formas de provimento para a função da direção escolar. Na conclusão destaca-se como, muitas vezes, modelos teóricos não dão conta da riqueza e da diversidade das práticas de gestão escolar. Nessa perspectiva, os sentidos nas escolas não permitem 
modelos fundados em verdades, dada a presença de múltiplos sentidos e práticas em construção; portanto, as teorias precisam contribuir de forma mais efetiva, e não de maneira prescritiva.

CAMARGO, Rubens Barbosa de; OLIVEIRA, João Ferreira de; CRUZ, Rosana Evangelista da; GOUVEIA, Andréa Barbosa. Problematização da qualidade em pesquisa de custo-aluno-ano em escolas de educação básica: relatório de pesquisa. Brasília: Inep, 2006. (Pesquisa Nacional Qualidade na Educação, [2]). Disponível em: $<$ http://portal.inep.gov.br/documents/186968/484184/Pesquisa + nacional + qualida de +na +educa\%C3\%A 7\%C3\%A3o + Vol + 2/b0605fff-5908-4e0f-86b1417225e106f4?version=1.2>. Acesso em: 23 jun. 2020.

O relatório apresenta contribuições para a problematização do conceito de qualidade que está presente nos relatórios estaduais da pesquisa "Levantamento do custo-aluno-ano em escolas de educação básica que oferecem condições para a oferta de um ensino de qualidade". Para a análise foi selecionada uma amostra de 82 escolas públicas de educação básica (entre urbanas e rurais, distribuídas nos estados de Goiás, Pará, Paraná, Piauí, Rio Grande do Sul, São Paulo e Ceará), cuja característica central foi o seu reconhecimento como escola de boa qualidade. O estudo realiza a análise de alguns componentes do custo-aluno-ano e de outras relações qualitativas das escolas da amostra, assim como a análise crítica de elementos discursivos, presentes nas observações e interpretações de pesquisadores e nas representações dos agentes escolares entrevistados. Define categorias que possam melhor explicitar o conceito de qualidade e que enfatizam alguns aspectos gerais dos custos das escolas, algumas condições para a oferta de um ensino de qualidade, além das percepções dos agentes escolares que confirmam e informam o que vem a ser qualidade nas escolas pesquisadas.

CURY, Carlos Roberto Jamil. A qualidade da educação brasileira como direito. Educação \& Sociedade, Campinas, v. 35, n. 129, p. 1053-1066, out./dez. 2014. Disponível em: < https://www.scielo.br/pdf/es/v35n129/0101-7330-es-35-129-01053. pdf>. Acesso em: 15 jun. 2020.

A qualidade é um dos elementos próprios da educação, tendo em vista ser um direito social e ter entre seus princípios norteadores o resguardo da cidadania, além de constituir-se como um dos pilares dos direitos humanos. A qualidade da educação está prevista em marcos legais sob perspectivas diversas. Na Constituição Federal de 1988, o art. 206 (VII) assevera a garantia de certo padrão e na Lei de Diretrizes e Bases (LDB) de 1996, o termo qualidade aparece dez vezes. O autor ressalta a importância do Pacto pela Valorização do Magistério e Qualidade da Educação, resultado da Conferência Nacional de Educação, realizada em 1994, que teve como principais temáticas o Plano Decenal de Educação para Todos e a busca 
de um Acordo Nacional de Educação para Todos. Os diferentes marcos legais instituídos de 1996 a 2014 constituem uma oportunidade rara e histórica para o Brasil superar a pesada herança do passado excludente e avançar em políticas rumo à verdadeira educação de qualidade. A articulação dessas medidas e a vontade de efetivar propósitos e metas possibilitarão a ampliação do acesso à educação revestida do ansiado padrão de qualidade.

DOURADO, Luiz Fernandes; OLIVEIRA, João Ferreira de; SANTOS, Catarina de Almeida. A qualidade da educação: conceitos e definições. Brasília: Inep, 2007. Disponível em: < http://portal.inep.gov.br/documents/186968/485287/A + qualidad e +da + educa\%C3\%A7\%C3\%A3o + conceitos +e +defini\%C3\%A7\%C3\%B5es > . Acesso em: 15 jun. 2020.

Revisão de literatura envolvendo o levantamento de estudos, avaliações e pesquisas e, ainda, a contribuição dos países membros da Cúpula das Américas mediante instrumento de coleta de dados. Identifica condições, dimensões e fatores fundamentais do entendimento do que seja educação de qualidade, considerando a ótica de organismos multilaterais, a exemplo da Unesco e do Banco Mundial. Busca contribuir com a produção de uma matriz teórico-conceitual que subsidie a discussão de políticas voltadas à garantia da qualidade da educação na região, levando em conta, sobretudo, os compromissos, os marcos políticos e as experiências implementadas por diferentes países membros. O estudo ressalta que a análise da qualidade da educação deve ter uma perspectiva polissêmica, envolvendo condições intra e extraescolares, bem como diferentes atores individuais e institucionais. Além disso, destaca que a discussão sobre qualidade da educação implica o mapeamento de diversos elementos para qualificar, avaliar e precisar a natureza, as propriedades e os atributos desejáveis ao processo educativo, tendo em vista a produção, organização, gestão e disseminação de saberes e conhecimentos fundamentais ao exercício da cidadania e, sobretudo, a melhoria do processo de ensino-aprendizagem.

FREITAS, Luiz Carlos de. Qualidade negociada: avaliação e contra-regulação na escola pública. Educação \& Sociedade, Campinas, v. 26, n. 92, p. 911-933, Especial, out. 2005. Disponível em: < https://www.scielo.br/pdf/es/v26n92/v26n92a10.pdf>. Acesso em: 25 jun. 2020.

A "qualidade negociada" é proposta como alternativa de contrarregulação e apoio a processos de mudança complexos nas escolas. A qualidade é encarada como produto de um processo de avaliação institucional construído coletivamente, tendo como referência o projeto político-pedagógico da escola e a constituição de uma espécie de pacto entre diferentes atores, com a definição de compromissos e responsabilidades recíprocas. É ressaltada a inadequação de estratégias de difusão de mudanças a partir de um centro irradiador, sem ter como referência os problemas 
reais da escola e sem levar em conta o conhecimento já acumulado no interior da instituição. Enfatiza-se a importância da mobilização da escola para que ela construa o seu caminho de melhoria e, com isso, promova maior organização dos profissionais da educação e sensibilize todos os servidores para a relevância do seu trabalho. Cada escola deve se tornar um centro de reflexão sobre si mesma, sobre o seu futuro. Não é apenas o professor que deve ser reflexivo - é a escola que precisa ser reflexiva e isso inclui gestores, professores, funcionários, alunos e pais. A análise do conceito de "serviço público" procura entender suas características particulares, mostrando que, a exemplo das políticas públicas neoliberais (PSDB-PFL), as políticas públicas participativas (PT e aliados) também terão problemas se não reconhecerem as especificidades do setor, como a estabilidade e as relações específicas com o poder, com o dinheiro e com o tempo, e se não instalarem processos de avaliação negociados que criem compromissos pactuados e incentivem novas formas de organização nas relações internas das escolas.

GADOTTI, Moacir. Qualidade na educação: uma nova abordagem. São Paulo: Editora e Livraria Instituto Paulo Freire, 2010. Disponível em: < http://acervo.paulofreire. org:8080/jspui/bitstream/7891/3086/1/FPF_PTPF_12_084.pdf>. Acesso em: 20 jun. 2020.

Qualidade é apresentada como um conceito dinâmico, que se altera dependendo do contexto e, nessa visão, a sustentabilidade deve ser considerada central para ajudar a renovar velhos sistemas educacionais. A qualidade na educação está ligada à vida das pessoas e ao bem viver, acentuando os aspectos social, cultural e ambiental, portanto é necessário valorizar o ensino não só do simbólico, mas também do sensível e do técnico. Um dos conceitos sobre qualidade está associado à gestão democrática e à avaliação, pois a participação da sociedade na escola e a garantia de espaços de deliberação coletiva depende da melhoria da qualidade da educação e das políticas educacionais. Nesse sentido, o conceito também está relacionado a dimensões fora do ambiente escolar, como as características culturais e socioeconômicas dos agentes envolvidos no processo, sobretudo quando se considera o desempenho escolar, a formação docente e as condições de trabalho ofertadas. Destaca-se a necessidade de atualizar o ensino e as práticas tradicionais para que seja possível oferecer uma educação que atenda às necessidades da realidade social. Também são discutidos o papel e os efeitos das novas tecnologias no campo da educação.

SOUSA, Sandra Zákia. Concepções de qualidade da educação básica forjadas por meio de avaliações em larga escala. Avaliação, Uniso, Sorocaba, v. 19, n. 19, p. 407420, 2014. Disponível em: <http://www.scielo.br/pdf/aval/v19n2/a08v19n2.pdf>. Acesso em: 20 jun. 2020.

A avaliação educacional vincula-se, necessariamente, a um conceito de qualidade que expressa um projeto educacional e social. As críticas à avaliação em 
larga escala são feitas com base no Sistema de Avaliação da Educação Básica (Saeb) e no uso de seus resultados. Também são destacadas as questões curriculares, que incentivam um movimento de homogeneização do que se ensina no País, e a utilização do desempenho obtido pelos alunos, que vem, paulatinamente, subsidiando iniciativas de gestão de rede, com foco na promoção da qualidade da educação, e integrando padrões indicadores de determinadas características, como o Índice de Desenvolvimento da Educação Básica (Ideb). Nessa perspectiva, o objetivo do estudo é explorar que concepção de qualidade vem sendo disseminada pelas avaliações em larga escala, com destaque para a tendência em reduzir a noção de qualidade ao desempenho de alunos em testes. Em busca de alternativas, é apresentada a experiência realizada no município de Campinas desde 2002, em conjunto com o Laboratório de Observação e Estudos Descritivos, da Universidade Estadual de Campinas (Loed/Unicamp), e analisa-se o documento elaborado pelo Grupo de Trabalho de Avaliação da Educação Infantil em 2012, intitulado "Educação infantil: subsídios para construção de uma sistemática de avaliação". Tanto a experiência como o documento referendam a importância da avaliação para a melhoria da qualidade do ensino público, evidenciando a necessidade de ressignificar o papel apoderado pelas avaliações em larga escala para essa melhoria.

Silvana Malheiro do Nascimento Gama, mestre e doutoranda em Educação pela Universidade Federal Fluminense (UFF), é supervisora educacional e diretora de $1^{\circ}$ e $2^{\circ}$ ciclos da Rede Municipal de Educação de Niterói; e, na Rede Estadual do Rio de Janeiro, desde 1994, leciona disciplinas pedagógicas no Curso de Formação de Professores em nível médio (Curso Normal) com ênfase na supervisão de estágios. Pesquisadora do Grupo de Pesquisas em Gestão e Políticas Públicas em Educação (Nugeppe/UFF).

smalheiro2004@yahoo.com.br

Alba Valéria Baensi, mestre em Avaliação e Gestão da Educação Pública pela Universidade Federal de Juiz de Fora (UFJF) e doutoranda em Política, Educação, Formação e Sociedade do Programa de Pós-Graduação em Educação na Universidade Federal Fluminense (UFF), coordena o Grupo Estadual de Articulação e Fortalecimento dos Conselhos Escolares do estado do Rio de Janeiro (GAFCE-RJ) e é membro da coordenação colegiada do Fórum Estadual de Educação do Rio de Janeiro (Feerj). Pesquisadora do Núcleo de Estudos e Pesquisas em Gestão e Políticas Públicas em Educação (Nugeppe/UFF). Articuladora municipal dos Conselhos Municipais voltados para educação na Secretaria Municipal de Educação de Magé e diretora do polo CEDERJ/UAB no município de Magé.

albaensi@gmail.com

Recebido em 30 de junho de 2020

Aprovado em 11 de setembro de 2020 